\title{
Topics
}

\section{Predicted and Experimented Acceleration Profile of the Rocket Sled}

\author{
By Daisuke Nakata ${ }^{1)}$, Ami Kozu $^{2)}$, Jun YaJima ${ }^{1)}$, Kenji Nishine ${ }^{1)}$, Kazuyuki Higashino ${ }^{1)}$ \\ and Nobuhiro TANATSUGU ${ }^{1)}$ \\ ${ }^{1)}$ Aerospace Plane Research Center, Muroran Institute of Technology, Muroran, Japan \\ ${ }^{2)}$ NIPPI Corporation, Yokohama, Japan
}

(Received July 27th, 2011)

\begin{abstract}
In this paper, the world's first application of hybrid rockets to rocket sled system is described. By using $\mathrm{N}_{2} \mathrm{O}$ oxidizer which has self-pressurizing capability, simple handling and low-cost operation was enabled. On the other hand, accurate prediction of the time-velocity profile of the rocket sled becomes difficult because the thrust curve of the $\mathrm{N}_{2} \mathrm{O}$ hybrid rocket varies with the outside temperature. Based on the preliminary thrust measurement, we predicted the velocity profile of the rocket sled and compared to the actual sled run. Both were well agreed with an error of $10 \%$ in velocity.
\end{abstract}

Key Words: High Speed Test Track, Rocket Sled, Hybrid Rocket, Nitrous Oxide, Self-pressurization

\section{Nomenclature}

$$
\begin{array}{ll}
p & : \text { fill line pressure } \\
t & : \text { time } \\
x & : \text { distance from the start point } \\
T_{\text {out }} & : \text { outside temperature }
\end{array}
$$

\section{Introduction}

Rocket sleds on High Speed Test Track (HSTT) have been used as practical aerodynamic test platforms in United States for a long time ${ }^{1-3)}$. An aircraft model or a space capsule equipped on a sled is accelerated by rockets along the rail track and its behavior in high-speed (usually supersonic) condition is examined. This device is considered to be a missing link between wind tunnels and free flight, and useful for the confirmation of aeroelasticity or drag force measurement of fullscale framework.

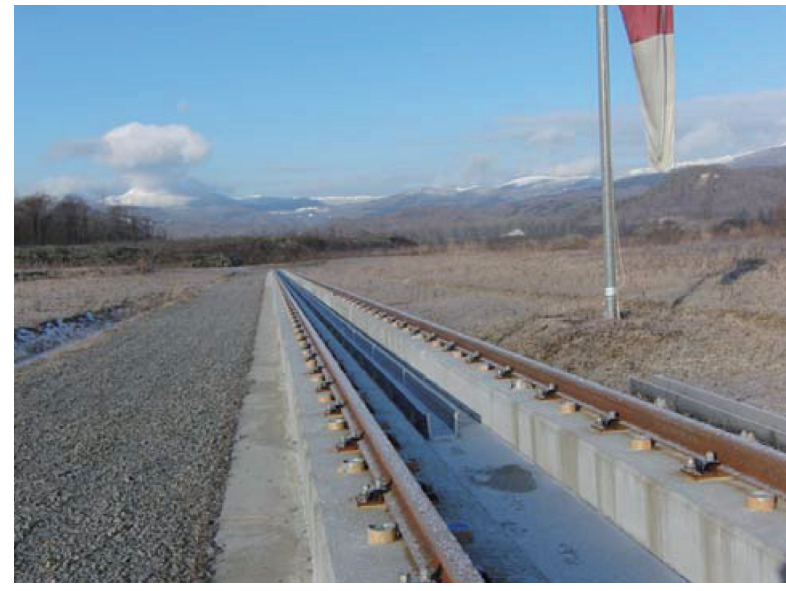

Fig. 1. High Speed Test Track (HSTT) constructed in the research field of Muroran Institute of Technology. The total length of the track is $300 \mathrm{~m}$ and the distance between the inside edges of the rails is $1.435 \mathrm{~m}$ (standard gauge). The water trough is fixed between the rails.

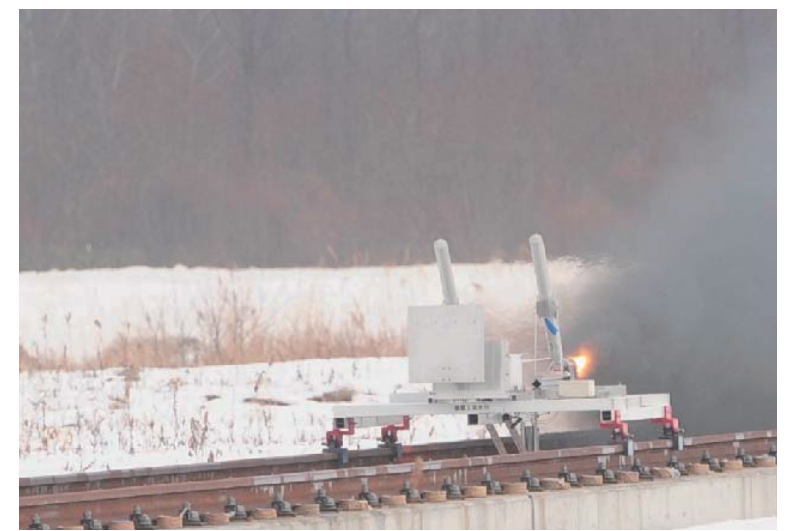

Fig. 2. Rocket Sled propelled by twin hybrid rockets along the test track. Sled body was mounted via four rail-grabbing slippers.

Muroran Institute of Technology developed the first rocket sled system in Japan to be used for high-speed aerodynamic studies. The test track $300 \mathrm{~m}$ in length and $1.435 \mathrm{~m}$ in width (standard gauge) was constructed in Shiraoi Test Field (Fig.1) in 2009. The sled body $2 \mathrm{~m}$ in length and $1.4 \mathrm{~m}$ in width (Fig.2) runs along the track propelled by multiple hybrid rockets. There are no examples of the application of hybrid rockets to the rocket sled acceleration in the world. In this paper, the process of the running profile prediction and the successful operation of the rocket sled with hybrid rocket is described.

\section{Hybrid Rockets}

Generally clustered solid motors are used as propulsion devices of a rocket sled due to their large thrust to weight ratio. 3 or 4-stage sleds are needed in order to reach hypersonic ( $>$ Mach 5) condition on the ground. However, when we aim at only subsonic operation, solid motors are not necessary. The propulsion system should be selected from the viewpoint of cost, safeness and easiness of handling. Hybrid rockets satisfy the above requirement and many applications for sounding rockets ${ }^{4)}$, manned sub-orbital flight ${ }^{5)}$ and small satellite launch system $^{6}$ are considered. 
Table 1. General characteristics of solid, liquid and hybrid rockets.

\begin{tabular}{|l|l|l|l|}
\hline & Solid & Liquid & Hybrid \\
\hline Initial Cost & Low & High & Mid. \\
\hline Running Cost & High & Low & Mid. \\
\hline Handling & Easy & Difficult & Easy \\
\hline Hazard Risk & High & Mid. & Low \\
\hline Thrust/Weight & High & Low & Mid. \\
\hline Isp & Low & High & Mid. \\
\hline
\end{tabular}

Table 1 shows the advantageous/disadvantageous point of each type of rocket system. Especially hybrid rockets are fascinating because of its lowest hazard risk and easiness of handling. Except for their high initial cost and complex handling process, liquid engines will be the best choice to lower the running cost. If our final goal is hypersonic running, clustered solid motor system must be used due to its largest thrust/weight ratio.

What we selected as a propulsion system of the rocket sled at first, commercial hybrid rocket "HyperTEK", . The operation system of HyperTEK is very simple, and no special licenses are required. A recent application for the model rocket launch is described by Habu et. $\mathrm{al}^{8)}$. The use of nitrous oxide $\left(\mathrm{N}_{2} \mathrm{O}\right)$ as oxidizer enables easy handling. Nitrous oxide has a strong vapor pressure and keeps liquid phase at room temperature. Therefore, no external pressurizing source or no cryogenic system is necessary. This enables us quite simple onboard propulsion system.

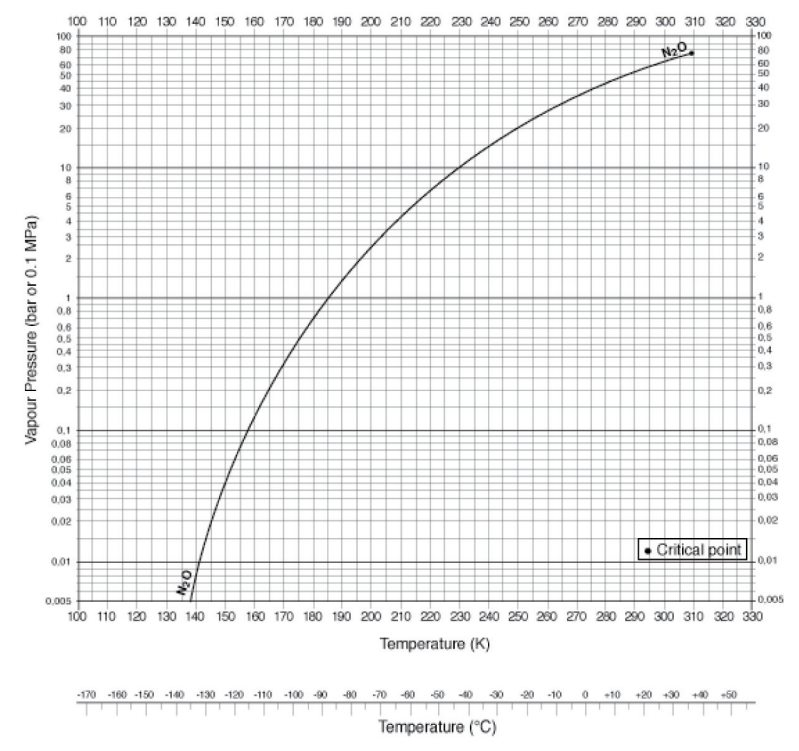

Fig. 3. Vapor pressure of nitrous oxide ${ }^{9)}$.

The biggest issue compared to the externally pressurized system, there is some difficulty when estimating the oxidizer flow profile, which is the most critical parameter to estimate the thrust profile. As the amount of oxidizer decreases, the tank pressure also gradually decreases ${ }^{10)}$. Besides, the vapor pressure of nitrous oxide strongly changes with the outside temperature (Fig. 3). When predicting the running profile of the rocket sled, it is essential to take into consideration the all of the above effect.

\section{Experimental Apparatus}

\subsection{Hybrid rocket}

The official specifications of the hybrid rocket are shown in Table.2. It consists of $2800 \mathrm{cc}$ oxidizer tank and 75-mm diam., 400$\mathrm{mm}$ length grain fuel. The oxidizer tank and the grain case are connected via the injector bell, which makes swirl oxidizer flow.

Table 2. Official Specifications of HyperTEK L6257).

\begin{tabular}{|l|l|}
\hline Fuel & ABS plastic $(\mathrm{D} 75 \times \mathrm{L} 400 \mathrm{~mm})$ \\
\hline Oxidizer & Nitrous oxide $\left(\mathrm{N}_{2} \mathrm{O}\right)$ \\
\hline Peak Thrust & $1189 \mathrm{~N}$ \\
\hline Average Thrust & $625 \mathrm{~N}$ \\
\hline Burn Time & $8 \mathrm{~s}$ \\
\hline Total Impulse & $4951 \mathrm{Ns}$ \\
\hline Initial Weight & $5.189 \mathrm{~kg}$ \\
\hline Burn out Weight & $2.587 \mathrm{~kg}$ \\
\hline
\end{tabular}

In the ignition phase, optional GOX flow is introduced to the grain core. High voltage (9 $\mathrm{kV} \mathrm{AC})$ spark wire set in the grain core initiates firing.

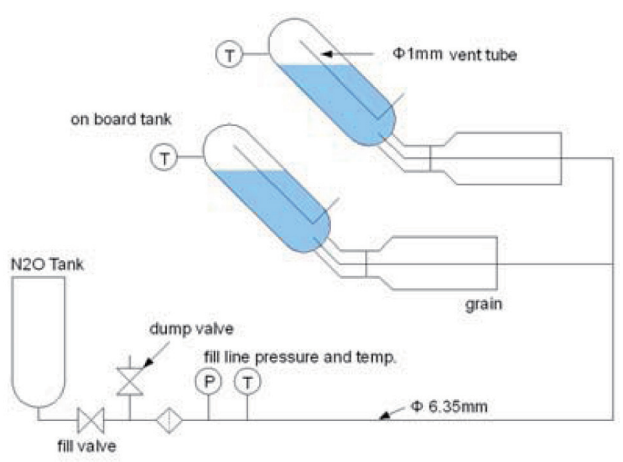

Fig. 4. Experimental apparatus of Rocket Sled Propulsion System. Fill-line pressure, fill-line temperature and surface temperature of onboard tanks are monitored.

\subsection{Test stand}

Before the sled running, the hybrid rocket was fired on the test stand, monitoring some physical properties (temperature, pressure and thrust). Experimental apparatus are shown in Fig.4. Vent tubes are inserted to the onboard tank. $45 \mathrm{deg}$. elbows are inserted between oxidizer tanks and injector bells because it is necessary to satisfy the following requirement simultaneously. (One can easily imagine these requirement are not satisfied in the case of vertical tank (90 deg.) or horizontal tank ( 0 deg.) configuration.)

1) When liquid $\mathrm{N}_{2} \mathrm{O}$ fills up, one can check the blow-out of $\mathrm{N}_{2} \mathrm{O}$ from the vent tube.

2) The bottom of the onboard tank should be fulfilled by liquid phase of oxidizer both before the run and during the run (strong G-force is applied).

The temperature was measured by resistance temperature detector (RTD) within the error of $0.5 \mathrm{~K}$. Onboard temperature sensors are equipped near the top of the tanks. The pressure 
was monitored by strain-gauge transducers within the error of $0.02 \mathrm{MPa}$. Load cell (FS 2kN) was equipped to the one of the hybrid rockets and its thrust was measured within the error of $10 \mathrm{~N}$. The burn time was determined by chopping off the ends of the curve when the thrust is below $5 \%$ of the maximum. The average thrust was determined as the total impulse during the $5 \%$-defined burn time, divided by the burn time.

\subsection{Onboard system}

Onboard system is almost same to the test stand system except that the onboard temperature sensors and the load cell are removed. Figure 5 shows the overview of hybrid rockets on the rocket sled. The sled body was made of steel; it is 1.4 $\mathrm{m}$ in width, $2.0 \mathrm{~m}$ in length along the running direction and $150 \mathrm{~kg}$ in weight including 2 rockets and Data Handling Unit (DHU). The sled body was mounted on the rails via four railgrabbing slippers. DHU includes a 3-axis acceleration sensor, aerodynamic drag measurement devices and anti-G data logger (MSR-160). The data logger withstands $15 \mathrm{G}$ and its sampling rate is $1024 \mathrm{~Hz}$ at maximum. In this study, $128 \mathrm{~Hz}$ sampling rate was chosen and time-integrated to know the velocity profile and the distance from the start point.

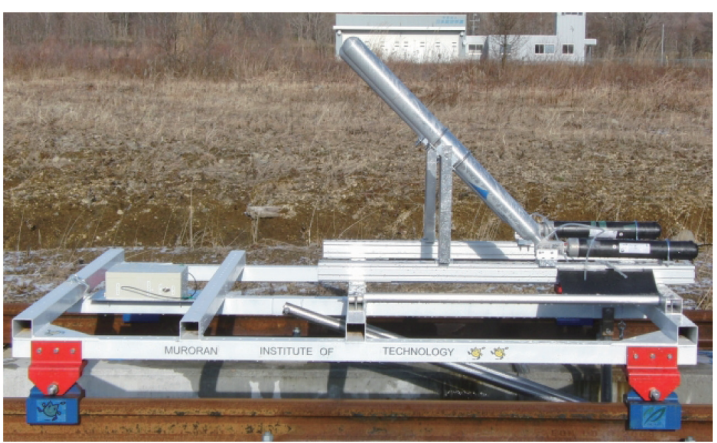

Fig. 5. The hybrid rockets on the sled. Small box equipped on the front of the sled is water-proof data handling unit (DHU), which includes 3-axis acceleration sensor and anti-G data logger.

Operators were at a distance of $150 \mathrm{~m}$ from the starting point of the rocket sled and remotely operated the fill valve and the firing switch. Water brake system was introduced to decelerate the sled ${ }^{11)}$. Metal plate (called bucket) located under the sled body runs into plenty amount of water filled in the water trough set between the rails (Fig.6). Initial water drag was controlled by changing the dipping area of the bucket.

The friction of the track is one of the important factors to predict the sled motion. This was measured by pulling the sled body by a car via a force sensor. The friction coefficient varies with the surface condition (dry or wet), but generally between $0.25-0.35$.

\section{Results and Discussion}

\subsection{Test stand experiment}

Measured thrust curve is shown in Fig. 7. The average and peak thrust is much lower than the official specification (Table.2), and the burn time is much longer. This is caused by the difference of ambient temperature.

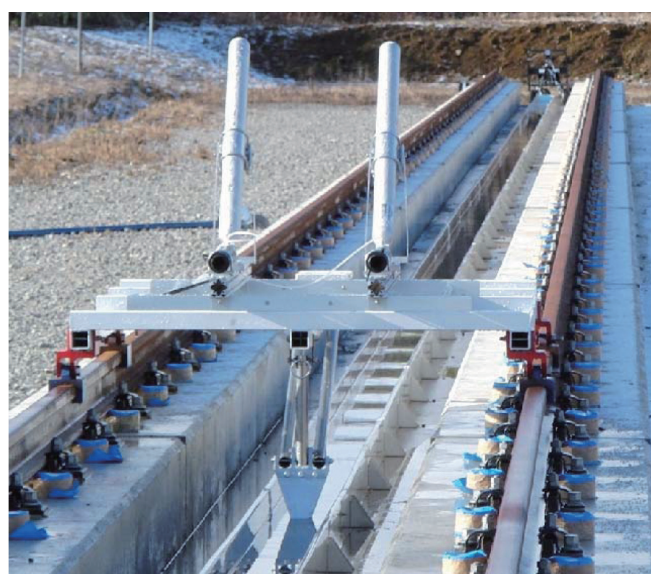

Fig. 6. The water brake system. When the metal plate under the sled body runs into the water trough, large water drag occurs and the sled is decelerated.

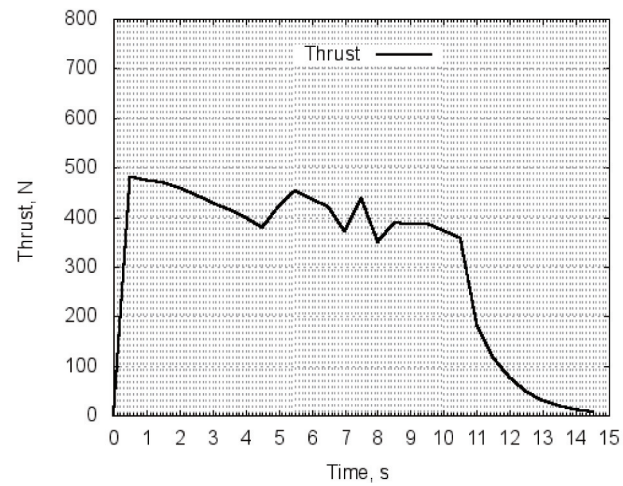

Fig. 7. Measured thrust curve of HyperTEK L625 at the test stand. The peak and the average thrust was $482 \mathrm{~N}$ and $347 \mathrm{~N}$, respectively. Burn time was $13.2 \mathrm{~s}$. The sampling rate was $2 \mathrm{~Hz} . T_{\text {out }}=279 \mathrm{~K}$.

Figure 8 shows the tank temperature profile. For 30 seconds after the fill valve opened, the tank temperature increases due to the compression of gas phase $\mathrm{N}_{2} \mathrm{O}$, then liquid-phase flow reaches to the onboard tanks and the temperature decreases due to the vaporization of $\mathrm{N}_{2} \mathrm{O}$. At $t=317 \mathrm{~s}$ (just before the ignition), the tank temperature was below zero and the internal pressure is considered to be $3.0 \mathrm{MPa}$ or less, judging from the vapor pressure of $\mathrm{N}_{2} \mathrm{O}$ (Fig.3). Pressure gauge equipped upstream of the fill line (Fig.9) also showed $p=2.44 \mathrm{MPa}$ at $t=317 \mathrm{~s}$. The onboard tank pressures are considered to be lower than this value.

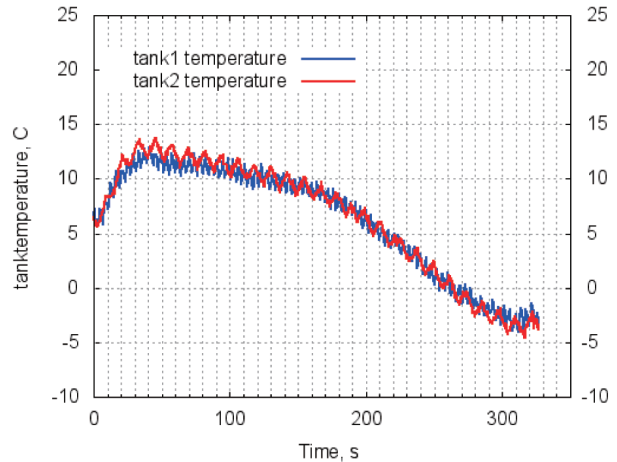

Fig. 8. The temperature profile of on board tank 1 and 2. $T_{\text {out }}=279 \mathrm{~K}$. The fill valve was opened at $t=0 \mathrm{~s}$ and closed at $t=317 \mathrm{~s}$. Firing was initiated at $t=319 \mathrm{~s}$. 


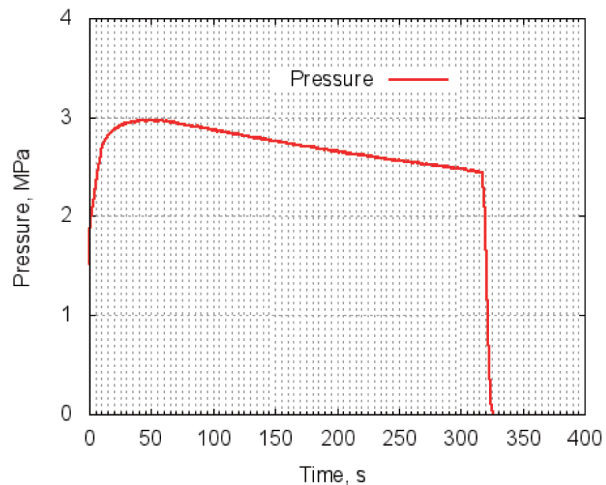

Fig. 9. The pressure of $\mathrm{N}_{2} \mathrm{O}$ fill line. The fill valve was opened at $t=0 \mathrm{~s}$ and closed at $t=317 \mathrm{~s}$. Firing was initiated at $t=319 \mathrm{~s}$. Just before the ignition, $p=2.44 \mathrm{MPa}$.

\subsection{Onboard experiment}

Figure 10 shows the pressure profile of $\mathrm{N}_{2} \mathrm{O}$ fill line before the sled run. The tank pressure just before the ignition was almost same to the case shown in Fig.9. The thrust curve is considered to be similar to the case of Fig.7. 2 rockets were almost simultaneously ignited as shown in Fig. 11 and the sled started to move after $1.5 \mathrm{~s}$ from the moment of ignition.

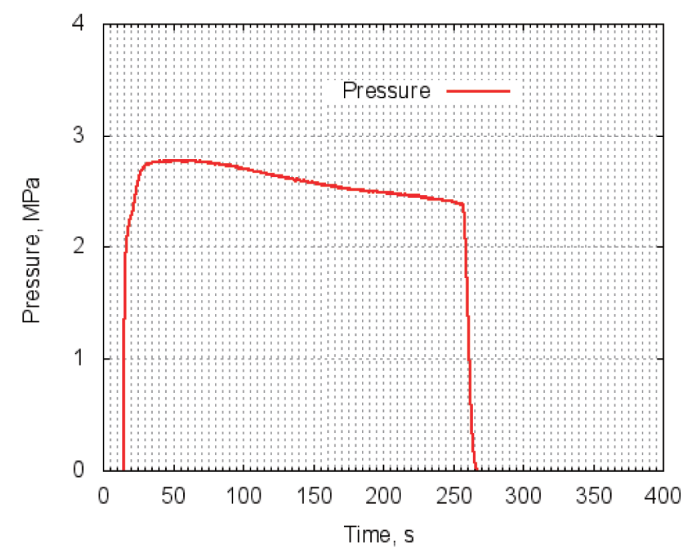

Fig. 10. The pressure profile of $\mathrm{N}_{2} \mathrm{O}$ fill line before the sled run. The fill valve was opened at $t=15 \mathrm{~s}$ and closed at $t=255 \mathrm{~s}$. Firing was initiated at $t=257 \mathrm{~s}$. Just before ignition, $p=2.39 \mathrm{MPa}$.

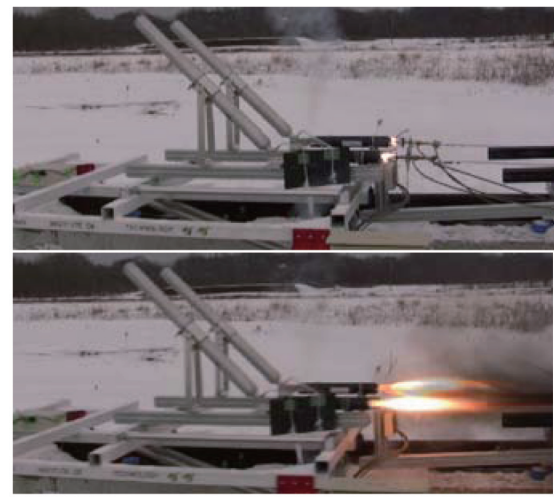

Fig. 11. Top: Simultaneous ignition of two rockets. Bottom: The sled started to move after $1.5 \mathrm{~s}$ from the upper figure.

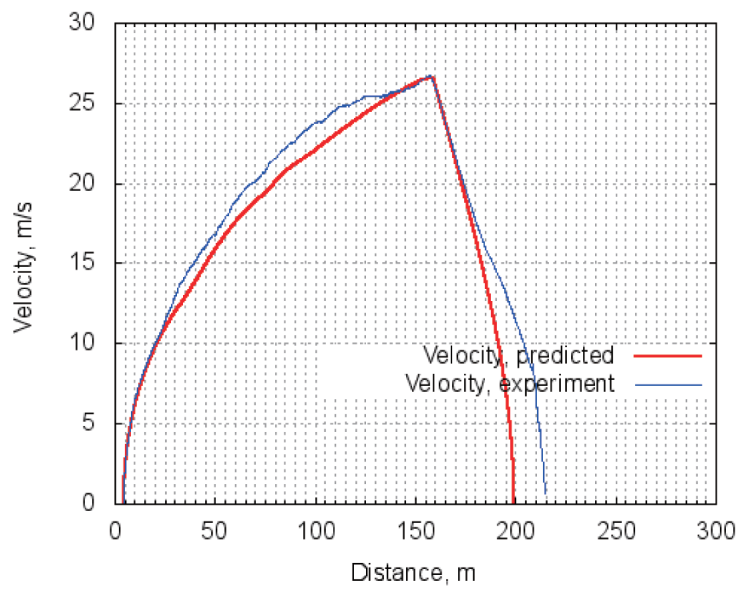

Fig. 12. Predicted and experimented velocity profile against distance. The sled starts from $x=4.4 \mathrm{~m}$ and runs into water trough at $x=159 \mathrm{~m}$. The maximum speed is $26 \mathrm{~m} / \mathrm{s}$ just before the entrance of the water trough.

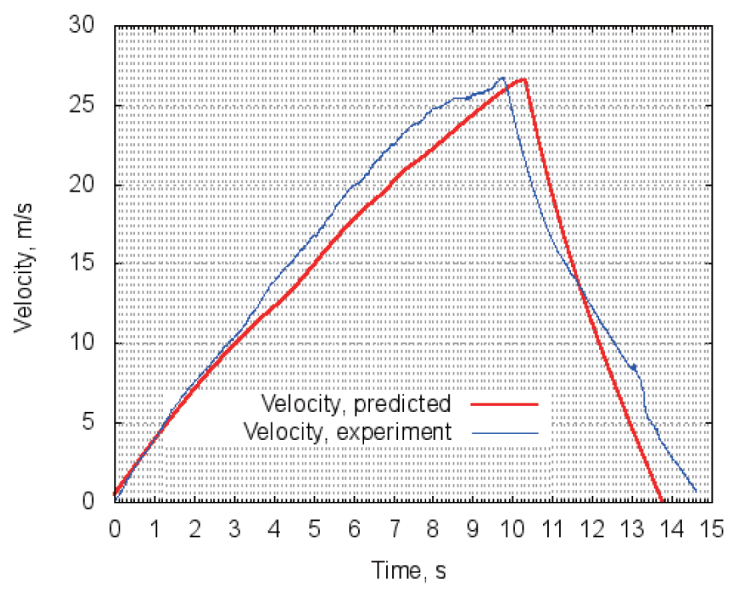

Fig. 13. Predicted and experimented velocity profile against time. Bright flame was observed until $t=14 \mathrm{~s}$.

Figures 12 and 13 show the estimated sled velocity profile calculated from the thrust curve obtained at the stand test (shown in Fig.7) and actual velocity profile of the running sled. Experimented velocity profile was obtained by integrating the acceleration profile (3-axis acceleration sensor) with Euler method. In the estimation, mass reduction of the grain fuel was assumed to be proportional to the instantaneous impulse at each time step. Air drag was also taken into consideration in the calculation, but it was negligible compared to the rail friction. Estimated and experimental motion profiles are very similar within the error of $10 \%$ in velocity. The burn time of both rockets also well agreed with that of test stand experiment. Bright flame was observed for both rockets until $t=14 \mathrm{~s}$ and vanished at the same moment of the halt of the sled. Some irregular change in the actual profile (ex. $t=13 \mathrm{~s})$ might be caused by the local friction enhancement. (If the inner surface of the slipper attaches to the lateral side of the rail, the friction suddenly increases.) Overall, the prediction error is within a satisfactory level.

In order to increase the maximum speed of the sled, it is necessary to establish much more accurate sled motion prediction tool. One of the key issue is the accurate prediction 
of the oxidizer flow depending on the outside temperature. Although the simple model is available $\mathrm{e}^{10)}$, it is considered that the onboard tank condition is not in the ideal thermal equilibrium condition. As the thrust/weight ratio increases, the relative importance of the rail friction will decrease.

\section{Conclusion}

The world's first application of hybrid rockets to the rocket sled was described. We introduced self-pressurizing $\mathrm{N}_{2} \mathrm{O}$ oxidizer without any onboard valve or any heat controller in order to simplify the handling process and reduce the operation cost as much as possible. The thrust of a hybrid rocket was measured at the test stand, and the sled motion on the High Speed Test Track was predicted taken into consideration rail friction, air drag and mass reduction of the grain fuel. Predicted and actual velocity profiles were agreed with each other within $10 \%$ error.

\section{References}

1) Krupovage D. J. : Wind-Tunnel and Full Scale Forces on Rocket Sleds, Journal of Spacecraft, 4, No. 10 (1967), pp. 1346-1351.

2) McSpadden H. J. : The History of Hurricane Mesa Test Facility, AIAA Paper 2004-3336

3) Rigali D. J. and Feltz L. V. : High-Speed Monorail Rocket Sleds for Aerodynamic Testing at High Reynolds Numbers, Journal of Spacecraft, 5, No. 11 (1967) pp. 1341-1346.

4) Ono T., et. al. : Collaborative Sounding Rocket launch in Alaska and Development of Hybrid Rockets, Space Technology Japan, 7 (2009), Tu_41-Tu_45.

5) $\mathrm{http}: / /$ www.scaled.com/projects/tierone/propulsion retrieved on $9^{\text {th }}$ Apr. 2011.

6) Watanabe, M. et. al. : Development study of Hybrid Rocket Booster for Ballistic Lounch of Small Satellite, Journal of the Japan Society of Microgravity Application, 9-2 (2002), pp.112-116.

7) http://www.hypertekhybrids.com/ retrieved on $9^{\text {th }}$ Aor. 2011.

8) Habu, H. et. al. : The Launch Test of Hybrid Rockets and Its Range Safety, Space Technology Japan, 9 (2010), pp.15-21. (in Japanese)

9) http://encyclopedia.airliquide.com/images_encyclopedie/ VaporPressureGraph/Nitrogen_Oxide_Vapor_Pressure.GIF, retrieved on $9^{\text {th }}$ Apr. 2011.

10) Akiba R., et. al.:Leading Stadies of the Staged Combustion Hybrid Rocket, Transactions of JSASS., 51 (2003), pp.141-150. (in Japanese)

11) Kozu A. : A Study on Water Braking of the High-Speed Sled Track Facility, Master Theses of Muroran Institute of Technology (2011). 